\title{
A high-capacity cell macroencapsulation system supporting the long-term survival of genetically engineered allogeneic cells
}

\author{
Aurélien Lathuilière ${ }^{\mathrm{a}}$, Steffen Cosson ${ }^{\mathrm{b}}$, Matthias P. Lutolf ${ }^{\mathrm{b}}$, Bernard L. Schneider ${ }^{\mathrm{a}, *}$, \\ Patrick Aebischer ${ }^{\mathrm{a}}$ \\ ${ }^{a}$ Neurodegenerative Studies Laboratory, Brain Mind Institute, Ecole Polytechnique Fédérale de Lausanne (EPFL), Lausanne, Switzerland \\ ${ }^{\mathrm{b}}$ Laboratory of Stem Cell Bioengineering, Institute of Bioengineering, Ecole Polytechnique Fédérale de Lausanne (EPFL), Lausanne, Switzerland
}

\section{A R T I C L E I N F O}

Article history:

Received 21 August 2013

Accepted 20 September 2013

Available online 5 October 2013

\section{Keywords:}

Cell encapsulation

Drug delivery

Hydrogel

Allogeneic cells

Ex vivo gene therapy

\begin{abstract}
A B S T R A C T
The rapid increase in the number of approved therapeutic proteins, including recombinant antibodies, for diseases necessitating chronic treatments raises the question of the overall costs imposed on healthcare systems. It is therefore important to investigate alternative methods for recombinant protein administration. The implantation of genetically engineered cells is an attractive strategy for the chronic long-term delivery of recombinant proteins. Here, we have developed a high-capacity cell encapsulation system for the implantation of allogeneic myoblasts, which survive at high density for at least one year. This flat sheet device is based on permeable polypropylene membranes sealed to a mechanically resistant frame which confine cells seeded in a tailored biomimetic poly(ethylene glycol) (PEG)-based hydrogel matrix. In order to quantitate the number of cells surviving in the device and optimize initial conditions leading to high-density survival, we implant devices containing C2C12 mouse myoblasts expressing a luciferase reporter in the mouse subcutaneous tissue. We show that initial cell load, hydrogel stiffness and permeable membrane porosity are critical parameters to achieve long-term implant survival and efficacy. Optimization of these parameters leads to the survival of encapsulated myogenic cells at high density for several months, with minimal inflammatory response and dense neovascularization in the adjacent host tissue. Therefore, this encapsulation system is an effective platform for the implantation of genetically engineered cells in allogeneic conditions, which could be adapted to the chronic administration of recombinant proteins.
\end{abstract}

(c) 2013 Elsevier Ltd. All rights reserved.

\section{Introduction}

With the recent expansion of biological drugs including recombinant antibodies, an increasing number of therapeutic applications are based on chronic administration. However, these treatments face limitations related to the cost of producing complex recombinant proteins, and necessitate repetitive intravenous injections to achieve sustained therapeutic levels. These constraints prompt the development of alternative systems to deliver biological drugs. The implantation of ex vivo genetically modified cells provides a possible alternative for the continuous delivery of recombinant proteins. However, it is critical to devise systems to maintain long-term cell survival and consistent production of the therapeutic factor, control the dose of protein administered, and

\footnotetext{
* Corresponding author. Brain Mind Institute, EPFL-SV-BMI-LEN, Station 19, 1015 Lausanne, Switzerland. Tel: +41 216939505; fax: +41 216939520.

E-mail address: bernard.schneider@epfl.ch (B.L. Schneider).
}

retrieve the implanted cells in case the treatment needs to be halted. Encapsulated cell technology (ECT) is a promising concept based on the confinement of the grafted cells within a permeable device. In ECT, genetically engineered cells are seeded within a polymer capsule, mainly composed of a permeable membrane, which protects the grafted cells from any direct contact with the host immune system, and allows for the diffusion of oxygen and nutrients. As the implanted cells are partially immunoprotected, ECT is compatible with allogeneic transplantation. Therefore, a single characterized source of human cells is applicable to large cohorts of recipients. ECT has already been translated to clinical studies, e.g. for the delivery of neurotrophic factors in the eye, the brain or the spinal cord [1-4].

The engineering of macroencapsulation device for clinical application has to meet critical requirements. Overall device geometry determines cell content and thereby the rate of recombinant protein secretion. Also, it is important to achieve high cellular density inside the device in order to produce therapeutic levels of the recombinant protein. In addition, long-term survival of cells 
needs to be consistently achieved, possibly using cells that can selfrenew inside the device. These aspects critically depend on the supply of oxygen and nutrients. One approach improving long-term implant efficacy is to seed the cells at low density, using an artificial extracellular matrix allowing for their progressive expansion inside the device [5]. Capsule engineering and initial conditions at the time of implantation are critical to promote neovascularization, which in turn favors the expansion of cells inside the device.

To produce a system applicable to clinical testing, it is essential to use materials that satisfy the criteria imposed by regulatory agencies for medical devices. The assembly process has to be highly reproducible and compatible with large-scale production of a device with appropriate mechanical properties.

In order to address these questions, we have generated a high capacity ECT system based on a "flat-sheet" geometry adaptable to large amounts of transplanted cells. To facilitate the expansion of the cells inside the internal chamber, cells are mixed with an adaptable biodegradable polymeric hydrogel inside the device. Here, we present a systematic in vivo optimization of important parameters for ECT, including initial cell density, polymer membrane porosity and hydrogel matrix stiffness. Bioluminescence produced by luciferase-expressing C2C12 myoblasts is used to longitudinally monitor cells implanted in the macrocapsule [6], and determine the conditions leading to long-term cell survival inside the device.

\section{Materials and methods}

\subsection{Device engineering, assembly and quality control}

To generate flat sheet devices, an outer polymeric frame, porous membranes and reinforcement mesh were assembled by ultrasonic welding. Outer frames were manufactured by injection molding of USP VI grade medical polypropylene. Unsupported hydrophilic polypropylene porous membranes (Pall Corporation) and a $77 \mu \mathrm{m}$ monofilament polyester mesh (Reichelt Chemietechnik GmbH \& Co) were cut out using an ultrasonic cutting process. The device was then assembled in a two-step process. A first ultrasonic welding step sealed the membrane and mesh to the outer frame to generate one half of the final device. The second step tightly sealed two half pieces together by delivering ultrasounds at the level of the outer frame. For quality control, the sealing of each device was verified using an air-leak test. While immerged in sterile double distilled water, filtered air was injected at a pressure of $17.58 \mathrm{hPa}$ (2.5 Psi) for $5 \mathrm{~s}$. Devices showing pressure decay greater than 100 Pa over $5 \mathrm{~s}$ were discarded.

To facilitate the loading of the cells, a $1 \mathrm{ml}$ pipette tip was glued into the loading port using photopolymerizing medical grade glue (Loctite, Henkel). Assembled devices were gas sterilized with ethylene oxide before further use.

\subsection{Cell culture and genetic engineering}

The mouse C2C12 myoblast cell line was obtained from American Type Culture Collection (ATCC) and maintained in regular culture conditions $\left(37{ }^{\circ} \mathrm{C}, 5 \% \mathrm{CO}_{2}\right)$ in Dulbecco's Modified Eagle Medium (DMEM) supplemented with 10\% fetal bovine serum (FBS), penicillin $(100 \mathrm{U} / \mathrm{ml})$ and streptomycin $(100 \mathrm{U} / \mathrm{ml}$ ) (Life Technologies).

Firefly luciferase cDNA was subcloned into the pRRLSIN.cPPT.PGK-GFP.WPRE lentiviral vector (Addgene plasmid \#12252). Lentiviral vector particles pseudotyped with the VSVG envelope were used at multiplicity of infection of 1500 to generate a stable $\mathrm{C} 2 \mathrm{C} 12$ cell line expressing luciferase. Further details are described in Ref. [40].

\subsection{PEG hydrogel synthetic matrix}

Fibrin-mimicking synthetic hydrogels were formed as described [7] using Factor XIIIa (FXIIIa)-mediated cross-linking of 8arm-poly(ethylene glycol) (PEG) precursors end-functionalized with peptidic FXIIIa substrates, namely 8arm-PEG-MMP-Lys (40 kDa, MMP-Lys: Ac-FKGGGPQGIWGQ-ERCG-NH2, MW: $1717.9 \mathrm{~g} / \mathrm{mol}$ ) and 8armPEG-Gln (40 kDa, Gln: H-NQEQVSPL-ERCGNH2, MW: $1539.6 \mathrm{~g} / \mathrm{mol}$ ) [7,8]. To prepare $300 \mu \mathrm{L}$ of stoichiometrically balanced ([Lys]/[Gln] = 1) $1.5 \% \mathrm{w} / \mathrm{v}$ gels, $2.1915 \mathrm{mg}$ of 8 arm-PEG-Gln and $2.3085 \mathrm{mg}$ of 8arm-PEG-MMP-Lys were prepared in $200 \mu \mathrm{L}$ Tris buffered saline (TBS; $50 \mathrm{~mm}, \mathrm{pH} 7.6$ ) containing $50 \mathrm{~mm}$ calcium chloride and $100 \mu \mathrm{m}$ of the adhesion ligand TG-RGD (H-NQEQVSPL-RGDSPG-NH2; MW: $1539.6 \mathrm{~g} / \mathrm{mol}$ ). $95 \mu \mathrm{l}$ of cell suspension was added to this precursor solution, and crosslinking was induced by adding $5 \mu \mathrm{L}$ thrombin-activated FXIIIa (200 U/mL; FibrogamminP ${ }^{\circledR}$ from CSL Behring).

\subsection{Device loading and implantation}

Under sterile conditions, C2C12 myoblasts were harvested with $0.05 \%$ trypsinEDTA solution (Life Technologies) and resuspended in SKBM serum free myoblast culture medium (Lonza) after cell counting. Cell suspension ( $95 \mu \mathrm{l}$ ) was mixed to gel precursor solution as described above. Immediately after addition of FXIIIa, $250 \mu \mathrm{l}$ of the mix was loaded into the device using a $1 \mathrm{ml}$ pipette. As the injected volume exceeded the inner volume of the device, a fraction of the total volume was ultrafiltrating through the porous membrane. Each device was placed in a $15 \mathrm{ml}$ sterile tube on a rocking platform for about 5 min until gelation was initiated, and was incubated for $30-45 \mathrm{~min}$ at $37^{\circ} \mathrm{C}$ until complete gelation. The loading port was then cut out and the device was sealed with photo polymerizing medical-grade glue (Loctite, Henkel) The devices were maintained in $2 \mathrm{ml} \mathrm{SKBM}$ (6-well plate) for $24 \mathrm{~h}$ before implantation.

All experiments on animals were done according to the Swiss regulation on animal experimentation and the European Community Council directive (86/609/ EEC) for the care and use of laboratory animals. Animals had access to water and food ad libitum. Adult B6-albino C57BL/6J-Tyr ${ }^{\mathrm{c}-2 \mathrm{~J}} / \mathrm{J}$ female mice were anesthetized with isoflurane and devices were implanted on the back of the animal, in the subcutaneous tissue. The wound was closed with surgical staples and animals recovered in their home cage. Analgesia was provided by acetaminophen $2 \mathrm{mg} / \mathrm{ml}$ in drinking water for three days.

\subsection{Detection of luciferase activity in vitro}

To quantify luciferase expression from C2C12 cells, serial dilution of cells were plated in quadruplicates in a 96-well plate. The day after, shortly before analysis, conditioned medium was removed and fresh prewarmed medium containing $150 \mu \mathrm{g} / \mathrm{ml}$ D-luciferin (Biosynth) was applied. Repeated measurements were done on IVIS Spectrum imaging system (PerkinElmer) until signal reached a plateau. Immediately after acquisition, cells were harvested with trypsin-EDTA and counted using an automated cell counter (Countess, Invitrogen). To measure luciferase activity from cells inside devices in vitro, devices were placed into culture medium containing $150 \mu \mathrm{g} / \mathrm{ml}$ D-luciferin and scanned using a similar protocol.

\subsection{Bioluminescence monitoring in vivo}

Every two weeks, in vivo imaging was performed with an IVIS Spectrum imaging platform (PerkinElmer). The mice were injected intraperitoneally with filtered $150 \mathrm{mg} / \mathrm{kg}$ D-luciferin in sterile PBS, placed in the imaging chamber and scanned under isoflurane anesthesia. For each time point, one mouse was selected randomly to determine the time of peak distribution. For this animal, imaging was repeated every 3 min until the flux of emitted photons reached a plateau, which was used to define the time of peak distribution. The remaining cohort of mice was scanned at the same interval post-luciferin injection. Data were analyzed with Living Image Software (PerkinElmer) by delimiting a constant region of interest (ROI, fixed area) around the device and quantifying total radiance in photon $/ \mathrm{sec} / \mathrm{cm}^{2} / \mathrm{sr}$.

\subsection{Histological analysis of explanted devices}

At the end of experiment, mice were sacrificed by an overdose of pentobarbital Shortly after, devices were dissected and retrieved. Device were then fixed in $4 \%$ paraformaldehyde overnight at $4{ }^{\circ} \mathrm{C}$, dehydrated and processed for paraffin embedding. Samples were sliced on a microtome at a thickness of $3 \mu \mathrm{m}$. Sections were stained with Masson's trichrome or hematoxylin and eosin. To identify endothelial cells, immunohistochemistry against murine CD31 (rat anti-mouse CD31, clone SZ31, Dianova) was performed according to antibody manufacturer protocol. Briefly, sections were deparaffinized in toluol for $10 \mathrm{~min}$ and rehydrated in water. Antigen retrieval was performed in $10 \mathrm{~mm}$ citrate buffer $\mathrm{pH} 6.0$ for $20 \mathrm{~min}$ at $95^{\circ} \mathrm{C}$. After $10 \mathrm{~min}$ wash in PBS, endogenous peroxidases were quenched with $\mathrm{H}_{2} \mathrm{O}_{2} 3 \%$ for $10 \mathrm{~min}$ at room temperature (RT) and blocking buffer (3\% BSA + 5\% rabbit serum in PBS) was applied for $1 \mathrm{~h}$ at RT. Anti-mouse CD31 was incubated $1 / 50$ in blocking buffer overnight at $4{ }^{\circ} \mathrm{C}$. Biotinylated rabbit anti-rat IgG (Vector Laboratories) was applied $1 / 200$ for $1 \mathrm{~h}$ at RT for $\mathrm{DAB}$ revelation. Counterstain was performed with Harris hematoxylin.

\subsection{Statistical analysis}

Data are expressed as average \pm standard error of the mean (SEM). Statistical analysis was performed using the Statistica software (StatSoft Inc.). The alpha level of significance was set at 0.05 . One-way ANOVA or two-way repeated measures ANOVA with Fisher LSD post hoc analysis were performed.

\section{Results}

\subsection{Device assembly by ultrasonic welding}

In order to maximize the amount of cells surviving within a macroencapsulation device, we engineered a high capacity capsule 
intended for subcutaneous application. The "flat sheet" geometry was chosen to allow for large inner volume and facilitate implantation in the subcutaneous tissue. This design also provides large areas of permeable polymer membrane to maximize diffusion of oxygen and nutrients for metabolically supporting the cells inside the device. In order to reduce the distance between the grafted cells and host blood vessels, we used hydrophilic polypropylene membranes ( $\sim 100 \mu \mathrm{m}$ thick) and minimized inter-membrane spacing (100$300 \mu \mathrm{m})$. A major element in device design is an outer polymeric frame, which confers mechanical resistance and seals the membranes together. Membranes and frame are composed of thermoplastic polypropylene, a material compatible with ultrasonic welding. This technology was used for the tight and precise assembly of the device, including polyester reinforcement meshes apposed on the outer sides of the device (Fig. 1A). An energy director was implemented to focus the ultrasounds and guaranty welding tightness. Scanning electron microscopy confirmed the complete merging of the different elements following ultrasonic welding (Fig. 1B). We also verified that the ultrastructure of the porous membrane was not altered by exposure to ultrasounds (Fig. 1C). The overall dimensions of the implant were $27 \mathrm{~mm}$ long, $12 \mathrm{~mm}$ wide and $1.2 \mathrm{~mm}$ thick. A port was integrated in the outer frame for loading the cells. Once the cells were loaded inside the capsule, the port was cut out and the device sealed with glue prior to implantation (Fig. 1D). Before utilization, all devices were quality controlled using an air-leak test and defective devices $(<10 \%)$ were discarded.

\subsection{Internal degradable artificial ECM}

Previous studies have shown that initial seeding of the capsule with cells at low density is critical to allow for proper engraftment [5]. The purpose of this approach is to avoid early metabolic failure in poorly vascularized conditions following device implantation. Later on, the surviving cells will expand as a function of oxygen and nutrient supply. This process might be facilitated over time as neovascularization develops. Because most cell lines compatible with long-term survival within an encapsulation device are adherent, it is essential to provide the cells with an artificial extracellular matrix (ECM) which will support their expansion and three-dimensional colonization of the device inner space. As the degradation of natural ECM components including collagen and laminin can produce foreign antigenic elements diffusing outside the device, it is preferable to instead develop alternative systems. Cells targeted for encapsulation can be mixed with a hydrogel precursor solution that is crosslinked shortly after loading in the flat sheet device to form a hydrogel network. To this end, we used a PEG-based hydrogel matrix. Furthermore, PEG is conjugated with peptides bearing a matrix metalloproteinase (MMP) substrate for progressive, cell-mediated degradation, as well as an RGD motif enabling cellular adhesion [8].

To determine how cells expand in the encapsulation device following implantation, we used the C2C12 myoblasts, a cell line that has successfully been used in preclinical models using
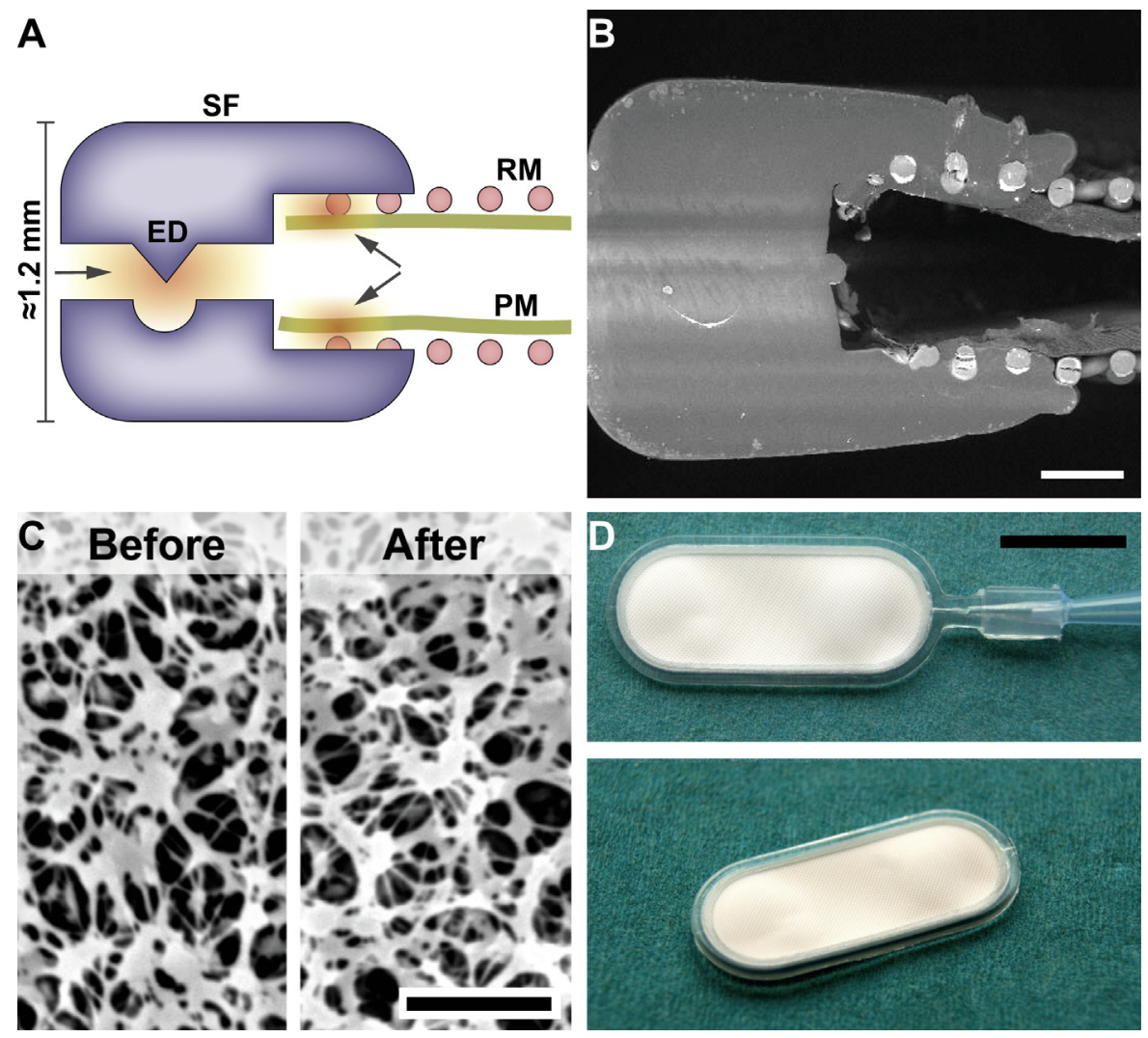

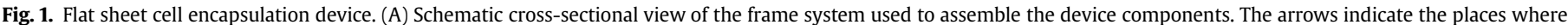

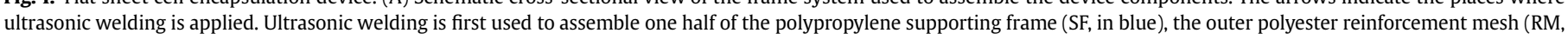

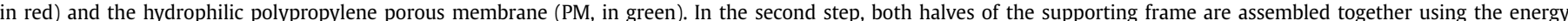

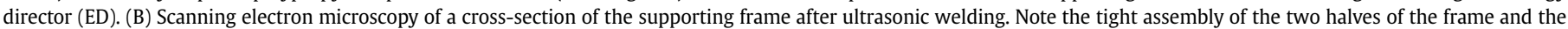

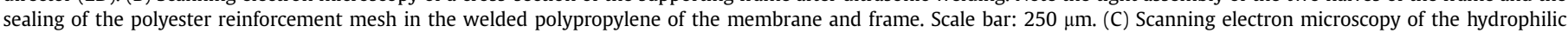

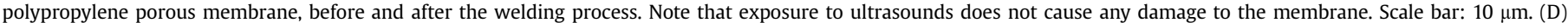

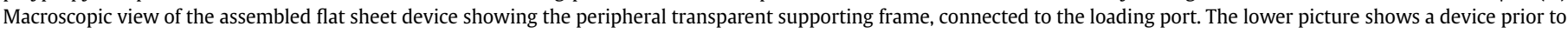
implantation, after removal of the loading port and sealing with glue. Scale bar: $10 \mathrm{~mm}$. 
macroencapsulation systems for the secretion of recombinant proteins $[5,9,10]$. C2C12 myoblasts were encapsulated in flat sheet devices using a modified PEG hydrogel as a matrix, and implanted in the mouse subcutaneous tissue. After one week, histological analysis of explanted capsules showed clusters of viable C2C12 cells within the hydrogel present in the center part of the device, and cells organized in dense layers close to the porous membranes (Fig. 2A,B). Some hydrogel filtering through the porous membranes during the loading procedure was also found on the outside of the capsule, scattered among the reinforcement mesh. As soon as 3 weeks post-implantation, the hydrogel outside the capsule was almost completely degraded (Fig. 2C,D). This rapid elimination of the PEG matrix is consistent with high MMP catalytic activity, which is likely to be induced by wound healing and tissueremodeling around the implant. Inside the device, dense hydrogel scattered in small areas was still visible at 3 weeks, but almost disappeared after 6 weeks in vivo (Fig. 2E,F). C2C12 myoblasts progressively expanded within the implant in parallel to matrix degradation.

\subsection{Monitoring of cell survival using the luciferase reporter}

In order to establish pre-implantation conditions leading to long-term, high-density survival of cells in the flat sheet
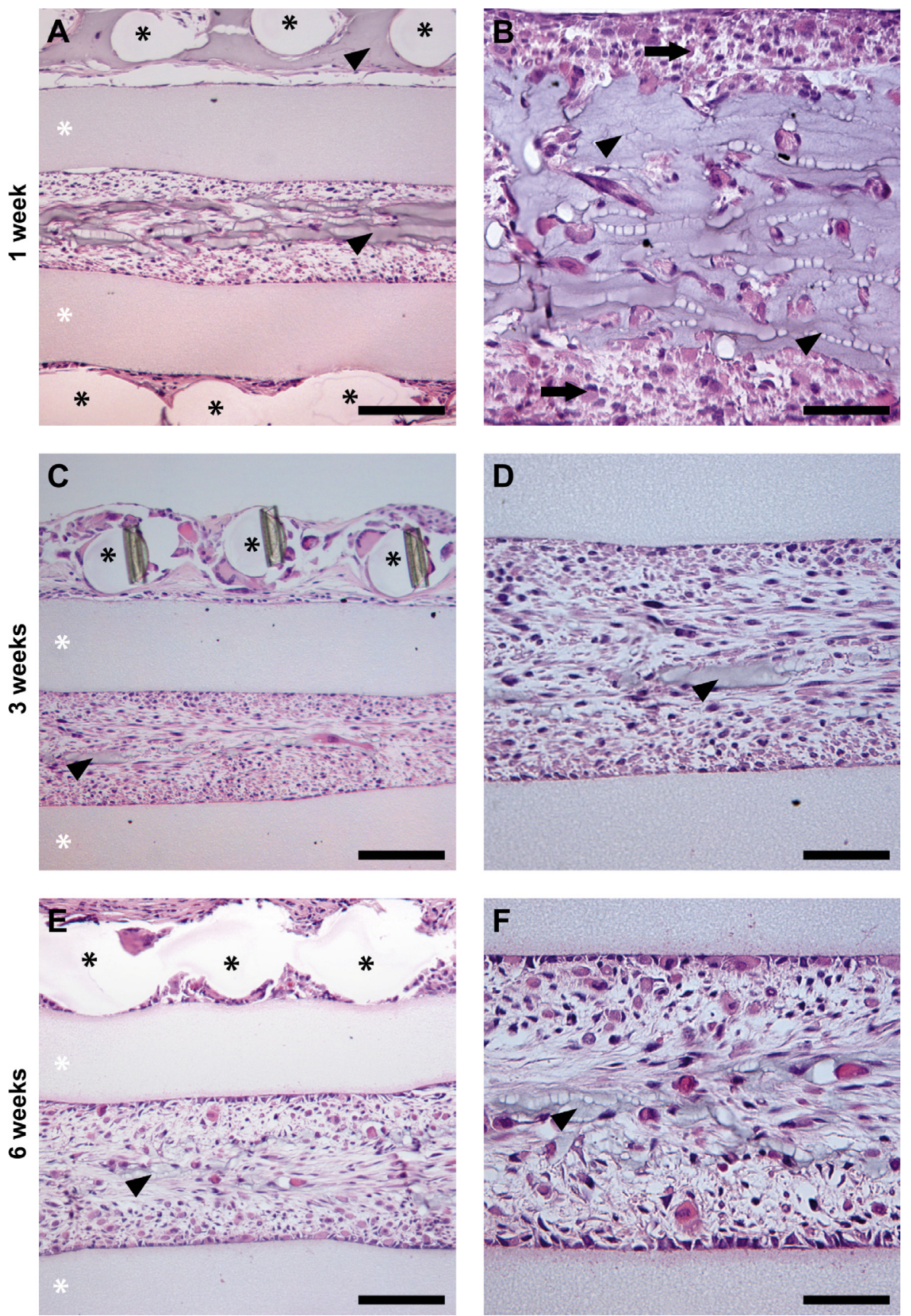

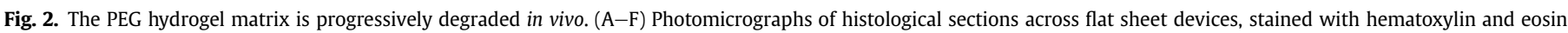

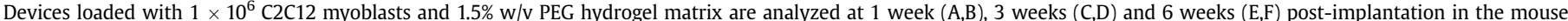

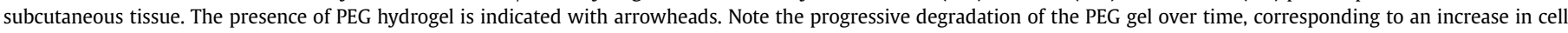
density inside the device. Scale bar: $100 \mu \mathrm{m}(A, C, D)$ and $50 \mu \mathrm{m}(B, D, F)$. White asterisk: polypropylene porous membrane; black asterisk: location of the polyester mesh. 
A

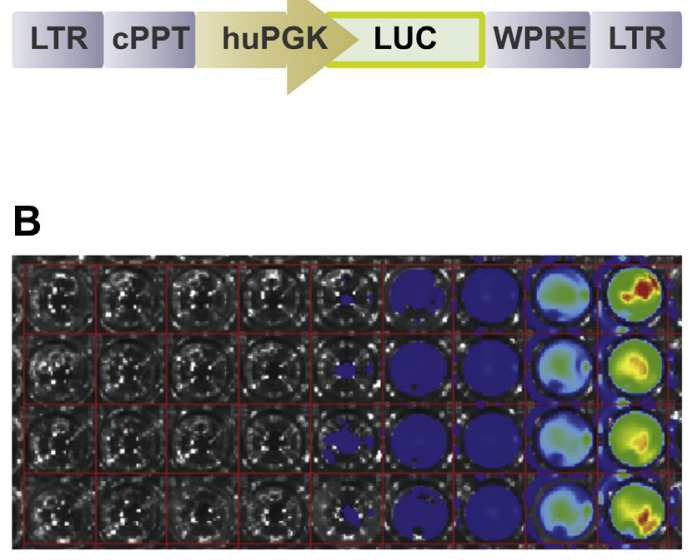

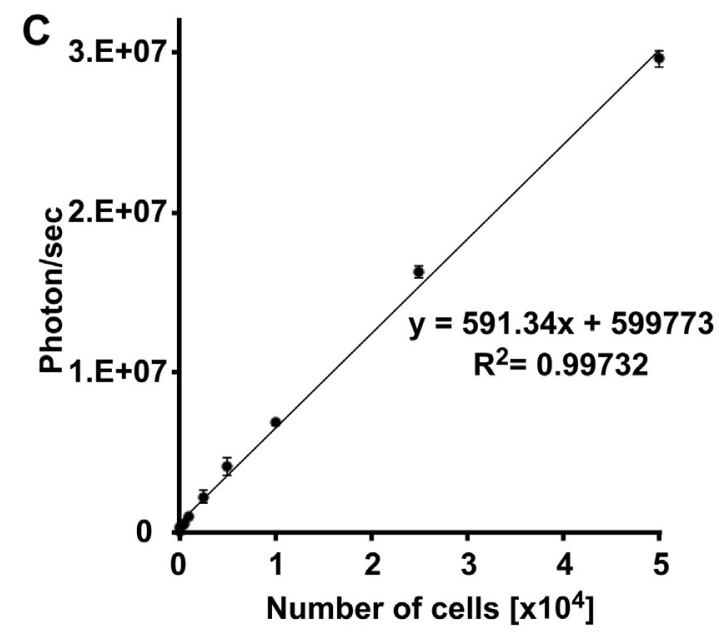

E

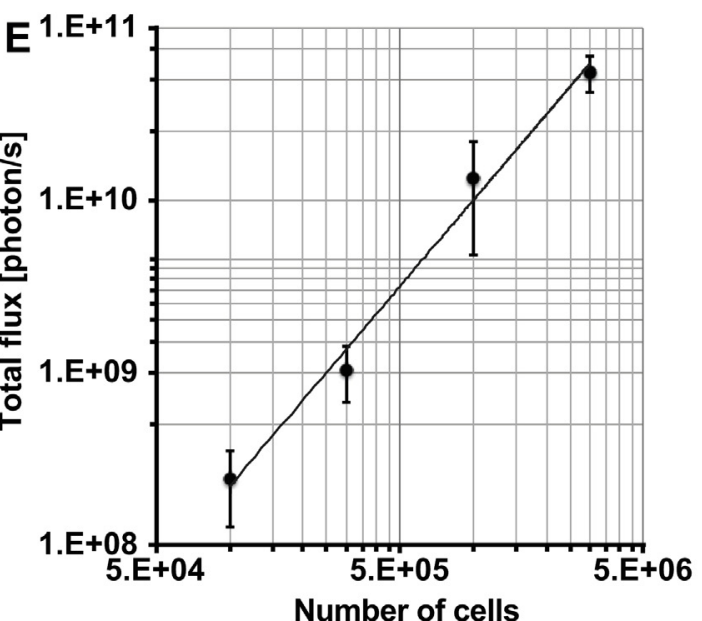

F 3 weeks

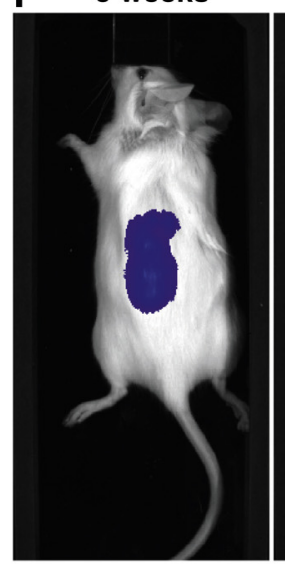

5 weeks

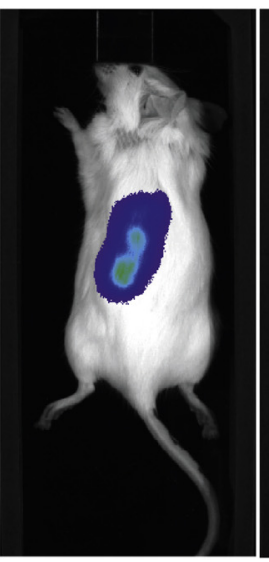

11 weeks

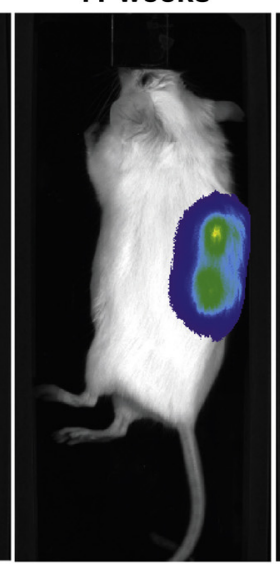

15 weeks

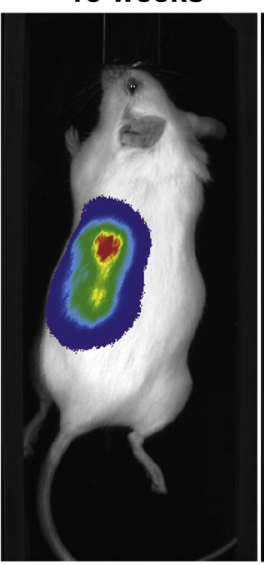

19 weeks

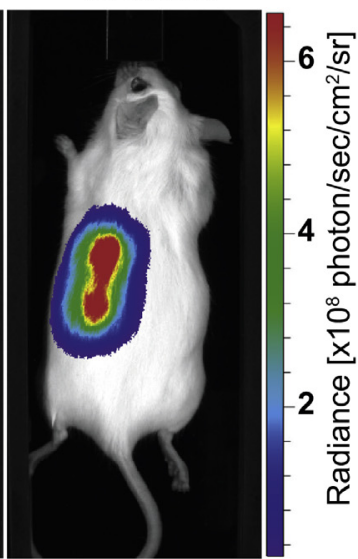

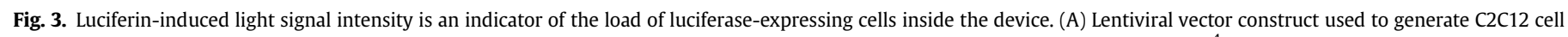

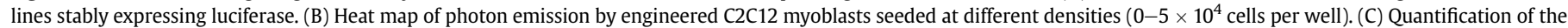

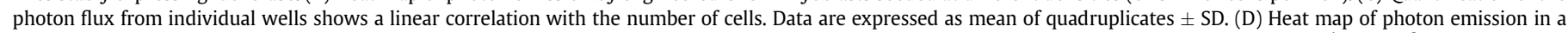

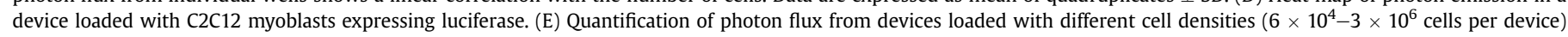

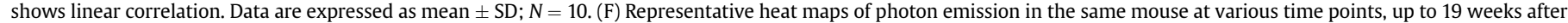
subcutaneous implantation of a flat sheet device containing luciferase-expressing C2C12 myoblasts.

encapsulation device, we used a luciferase reporter system as previously described [6]. A stable C2C12 cell line expressing the firefly luciferase under the pgk-1 promoter was generated by lentiviral transduction (Fig. 3A). Cells plated at different densities produced detectable bioluminescence following addition of luciferin in the culture medium (Fig. 3B). Quantification of emitted light revealed a linear relationship with the amount of living cells in each well (Fig. 3C). To verify that light could be effectively transmitted through the encapsulating membrane and mesh, similar measurements were performed on flat sheet devices loaded with 

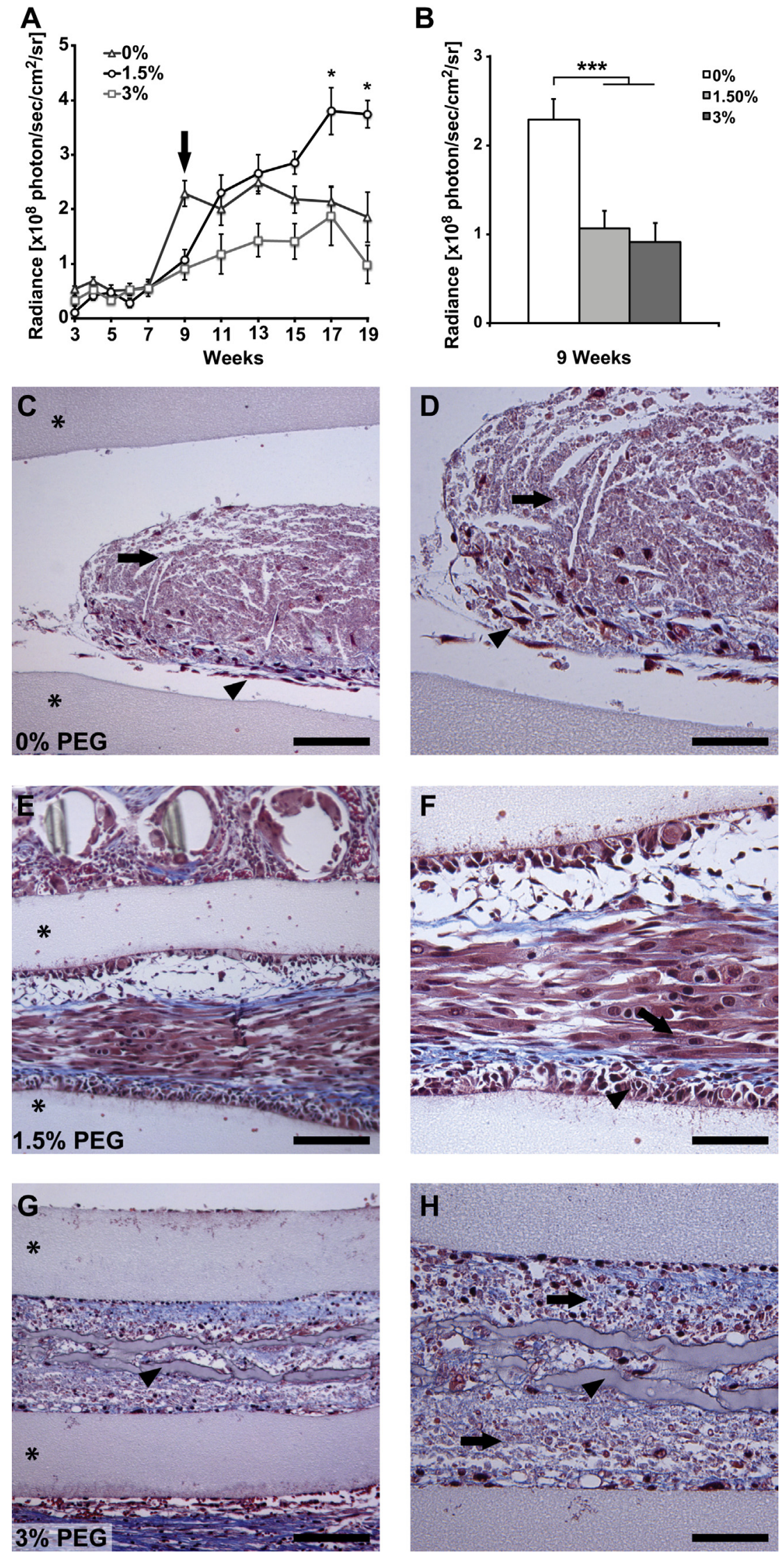

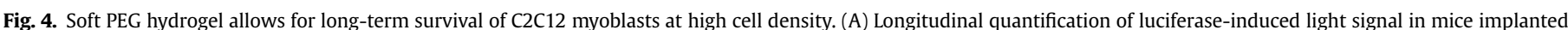

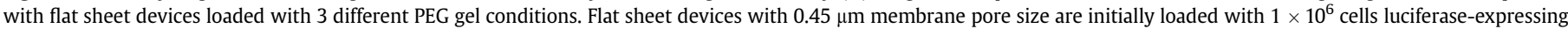

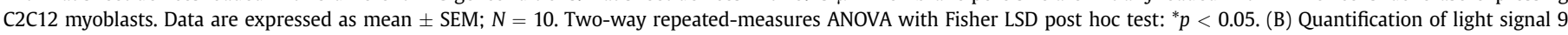


increasing amounts of $\mathrm{C} 2 \mathrm{C} 12$ myoblasts expressing luciferin (Fig. 3D). We indeed found the same relationship between the number of encapsulated cells and the measured flux of emitted photons (Fig. 3E). Hence, the same luciferase reporter system could be used to monitor the expansion and survival of encapsulated cells in vivo, by quantifying luciferin-induced bioluminescence in mice subcutaneously implanted with flat sheet devices (Fig. $3 \mathrm{~F}$ ). In the next series of experiments, we used this semi-quantitative approach to optimize three parameters that are key to cell survival inside the device: (1) the hydrogel polymer content, (2) membrane porosity and (3) the initial cell seeding density.

\subsection{Artificial ECM stiffness}

The presence of a synthetic ECM inside the device is an important factor for the early adaptation and expansion of cells after implantation. Synthetic hydrogel can be tailored for cell-specific requirements. Indeed, it has been demonstrated that the PEG hydrogel stiffness, which can be readily modified by altering the gel precursor concentration, affects cell proliferation and differentiation [11,12]. To test the effect of gel stiffness on the cell expansion rate and survival of $\mathrm{C} 2 \mathrm{C} 12$ myoblasts inside the device, we tested two different PEG gel concentrations. We compared devices (pore size $0.45 \mu \mathrm{m}$ ) loaded with same amount of luciferin-expressing cells ( $1 \times 10^{6} \mathrm{C} 2 \mathrm{C} 12$ myoblasts) either in the absence of hydrogel matrix, with $1.5 \% \mathrm{w} / \mathrm{v}$ PEG hydrogel or with $3 \% \mathrm{w} / \mathrm{v}$ PEG hydrogel, corresponding to a Young's modulus of $424.732 \pm 95.76 \mathrm{~Pa}$ (termed 'soft' gel for simplicity) and $2558.91 \pm 48.94$ Pa ('stiff gel), respectively. For each condition, we repeatedly measured the bioluminescence produced in living animals, as a proxy for the amount of bioactive cells contained in the implanted devices (Fig. 4A; note that for the sake of comparison, the radiance data of the test group with $1 \times 10^{6}$ cells, $1.5 \%$ PEG and $0.45 \mu \mathrm{m}$ porous membranes are also shown in Fig. 5A and D). During the first seven weeks after implantation, we could detect bioluminescence for all three conditions. During this period of time, the intensity of the signal did not increase over time, and only minor variations were measured between the tested conditions. In the second phase of implantation (week 7-19), we observed a clear progression in the intensity of the bioluminescence signal produced. In the absence of any hydrogel matrix, a rapid expansion occurred between week 7 and 9 , and the intensity of the emitted light was significantly higher at week 9 than in any of the other conditions (Fig. 4B). However, signal intensity did not further increase (Fig. 4A). Histological analysis of devices explanted at week 19 revealed disorganized cell clusters in some sections of the inter-membrane inner space, with large necrotic zones bordered by few living myoblasts (Fig. 4C,D).

With both soft and stiff gels, the progression of the bioluminescence signal was very similar until week 9 (Fig. 4A,B). However, from week 17 on, signal intensity further increased only in capsules loaded with soft hydrogel, reaching significantly higher values than in any of the other two conditions (Fig. 4A). Histological analysis revealed a highly dense mass of viable cells in this condition, confirming that enhanced bioluminescence reflects high cell survival inside the device (Fig. 4E). C2C12 myoblasts formed aligned clusters of cells indicative of myogenic differentiation (Fig. 4E,F). In contrast, the viability of the cells was reduced in devices initially loaded with 3\% PEG hydrogel, suggesting that the matrix was too stiff in this condition to support efficient expansion of $\mathrm{C} 2 \mathrm{C} 12$ myoblasts (Fig. 4G,H). Indeed, we found the presence of intact hydrogel patches even after 19 weeks in vivo. Overall, we found in this long-term experiment that soft hydrogel is the optimal condition to support encapsulated $\mathrm{C} 2 \mathrm{C} 12$ myoblast expansion in vivo.

\subsection{Membrane permeability and initial cell density}

We further tested in parallel experimental groups the effect of membrane porosity and initial cell load on the outcome of $\mathrm{C} 2 \mathrm{C} 12$ myoblasts implanted in flat sheet devices. The physical characteristic of the porous membrane is a critical parameter for the survival of encapsulated allogeneic cells. Porosity defines the rate of passive molecule diffusion across the membrane, which includes the inward diffusion of oxygen and nutrients, and the outward release of soluble factors. While inward diffusion is critical for metabolic supply to the implanted cells, factors released by the capsule might elicit an immune response. Additionally, membrane permeability has been proposed to affect the quantity of recombinant proteins delivered by macroencapsulation implants [13]. We compared the long-term survival of luciferase-expressing cells encapsulated using two types of polypropylene membranes, with pore sizes of either $0.22 \mu \mathrm{m}$ or $0.45 \mu \mathrm{m}$ (Fig. $5 \mathrm{~A}-\mathrm{C}$ ). Capsules were loaded with $1 \times 10^{6}$ C2C12 myoblasts with a soft PEG hydrogel. Bioluminescence was similar between the two conditions over the first 7 weeks postimplantation, and steadily increased in both conditions for the following 10 weeks (Fig. 5A). After 17 weeks, the bioluminescence signal in devices made of the $0.22 \mu \mathrm{m}$ porous membranes started to decline. Remarkably, the light signal produced by the device made of the most porous membrane increased more consistently and reached significantly higher values at week 19 . Histological analysis of the explanted devices revealed necrotic zones in the devices made with the $0.22 \mu \mathrm{m}$ porous membranes, especially in the central part of the cell mass where metabolic supply is most limited (Fig. 5B). In contrast, a thick layer of viable cells was found inside the $0.45 \mu \mathrm{m}$-porous device (Fig. $5 \mathrm{C}$ ). Therefore, membranes with smaller porosity are likely to limit the diffusion of oxygen and nutrients, which may fail to support the survival of the encapsulated cell mass.

Another approach to tune cell expansion as a function of oxygen and nutrient supply is to adapt the initial loaded cell density. We tested 3 different initial cell concentrations, $0.3,1$ and $3 \times 10^{6}$ cells. Cells were loaded with soft PEG hydrogel into devices assembled with $0.45 \mu \mathrm{m}$ pore-sized membranes. The in vivo monitoring of cell growth showed significant differences between these conditions (Fig. 5D). With an initial load of $0.3 \times 10^{6}$ cells, the signal stabilized after 9 weeks and there was no further expansion phase. In contrast, a steady increase was observed in the group loaded with $1 \times 10^{6}$ cells. Although capsule viability was excellent in both groups, the final cell density inside the device was lower in the capsules initially containing $0.3 \times 10^{6}$, as compared to $1 \times 10^{6}$ cells (compare Fig. 5E with C).

As expected, an initial load of $3 \times 10^{6}$ cells produced a more intense bioluminescence during the first 7 weeks (Fig. 5D). However, the signal did not further increase until week 19. Histological analysis revealed the presence of necrotic "ghost" cells inside the device (Fig. 5F). This necrosis is likely caused by initial cell overload, which was not adapted to restrictive metabolic conditions during the initial phase of implantation.

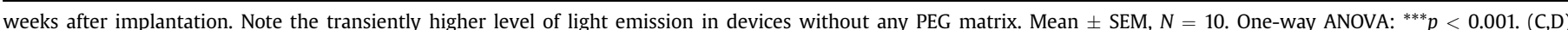

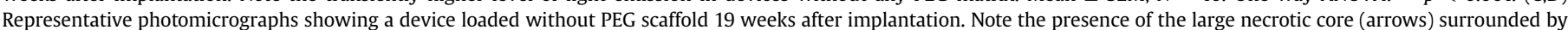

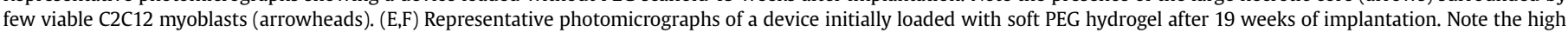

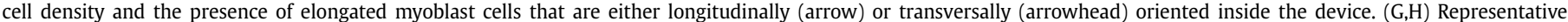

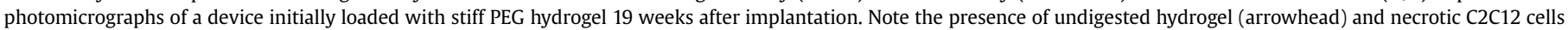
(arrows). Masson's trichrome staining. Scale bars: $100 \mu \mathrm{m}$ (C,E,G), $50 \mu \mathrm{m}$ (D,F,H). Asterisk: polypropylene porous membrane. 


\subsection{Long-term survival and differentiation in myofibers}

When loading parameters were set at an initial amount of $1 \times 10^{6}$ cells using a soft hydrogel matrix, we achieved high-density survival of myoblasts inside $0.45 \mu \mathrm{m}$ porous membranes. Histological analysis of the capsules at 19 weeks post-implantation revealed dense alignment of structures resembling myofibers formed by elongated $\mathrm{C} 2 \mathrm{C} 12$ cells (Fig. 6A). Myofibers were
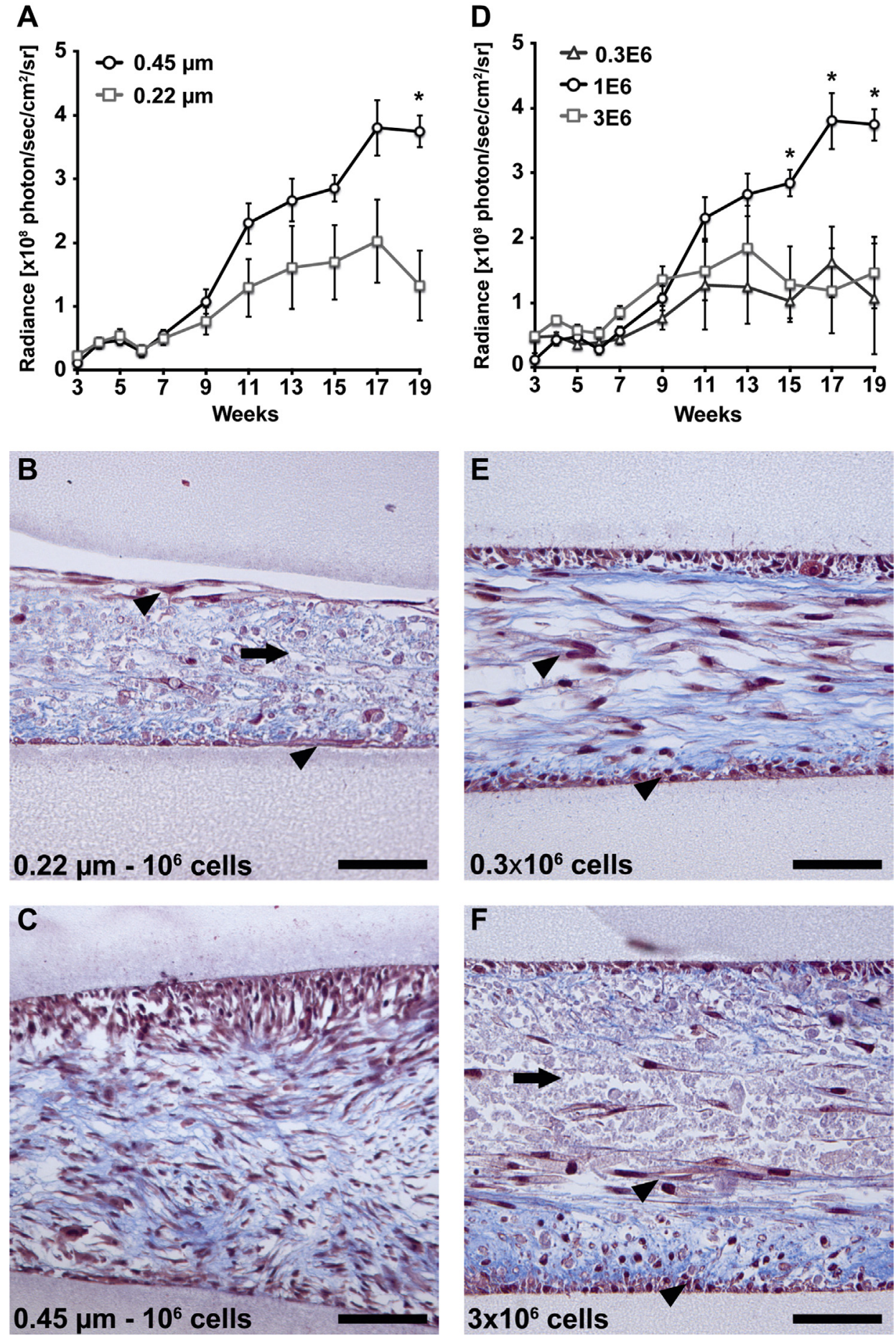

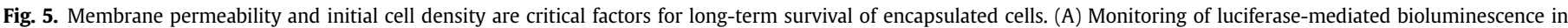

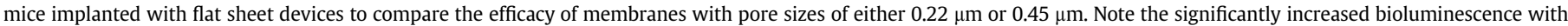

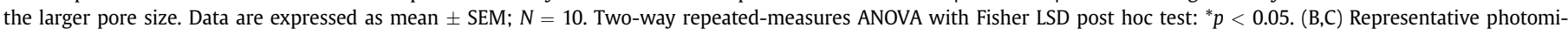

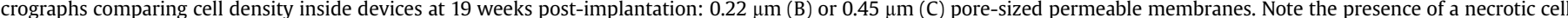

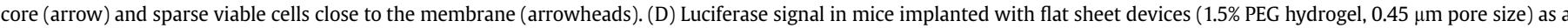

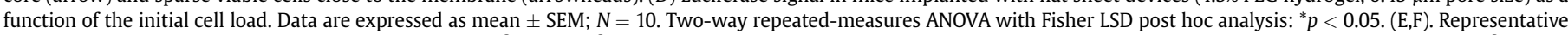

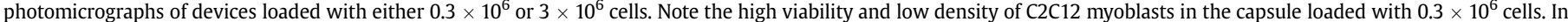

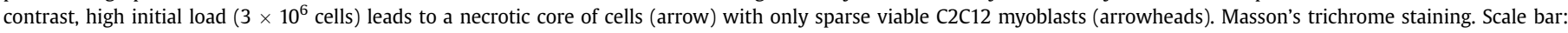
$50 \mu \mathrm{m}$. 

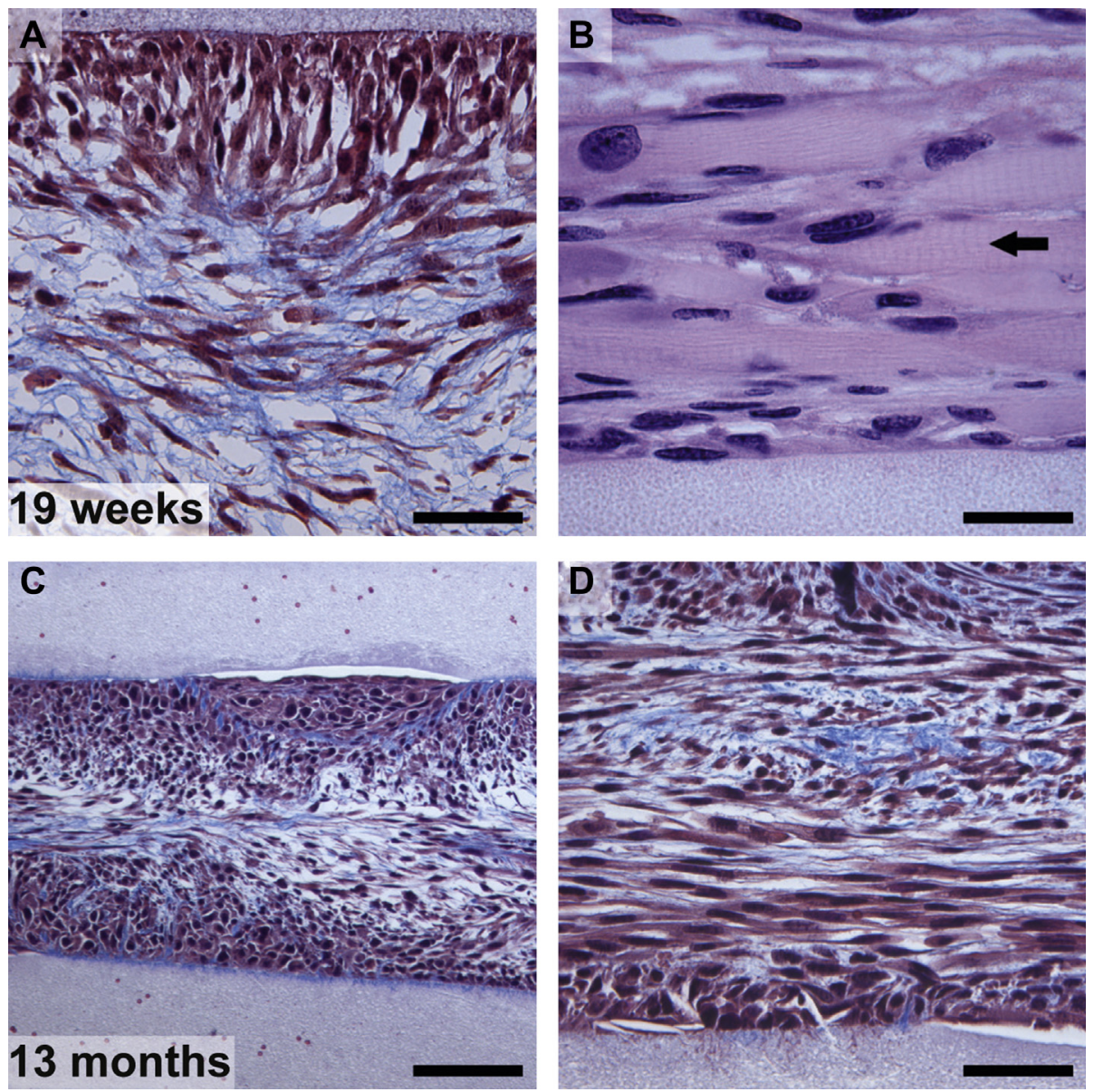

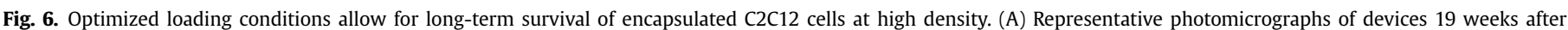

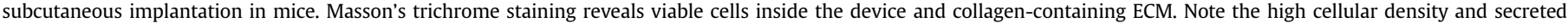

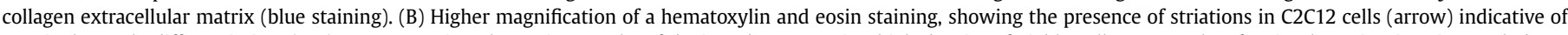

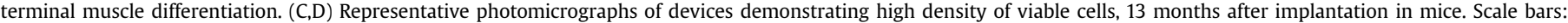
$25 \mu \mathrm{m}(\mathrm{A}, \mathrm{D}), 10 \mu \mathrm{m}$ (B), $50 \mu \mathrm{m}$ (C).

interspersed with ECM, which appeared blue following Masson's trichrome staining and was therefore mainly composed of collagen fibers (Fig. 6A,B). C2C12 myoblasts were therefore able to produce a dense supporting ECM following initial expansion in the PEG matrix and MMP-mediated degradation of the hydrogel. This microenvironment favored differentiation of $\mathrm{C} 2 \mathrm{C} 12$ myoblasts into striated myofibers, as revealed by hematoxylin and eosin staining (Fig. 6B). In a parallel chronic experiment based on the same conditions, histological analysis of devices retrieved after 13 months in vivo revealed a high density of surviving cells (Fig. 6C,D). Therefore, encapsulated myoblasts can long-term survive in the subcutaneous tissue.

\subsection{Neovascularization}

As described above, the access to oxygen and nutrients is a limiting factor, which directly affects the survival and expansion of the cells inside the encapsulating device. Oxygen and nutrient supply is primarily determined by the neovascularization that develops in close proximity to the implanted device. In the previous experiment, optimal conditions for implantation led to long-term survival of cells at high density in the flat sheet macroencapsulation device. Strikingly, a very dense neovascularization developed around the implants. Fig. 7A shows a representative image of the blood vessels present on the ventral side of the device,
19 weeks post-implantation. The reinforcement mesh provided a support for the growth of new blood vessels, penetrating through the mesh towards the porous membrane (Fig. 7B). Histological sections of the tissue lining the device confirmed the presence of a dense network of capillaries near the polymer membrane (Fig. 7C,D). Immunostaining for the angiogenesis marker CD31 confirmed the proliferation of endothelial cells adjacent to the membrane (Fig. 7E,F).

\subsection{Subcutaneous tissue reaction}

Next, we assessed the local host tissue reaction around the implant to verify its biocompatibility. After one week in vivo, some PEG hydrogel was still present on the outside of the membrane, around the reinforcement mesh (Fig. 8A). Few fibroblast-like host cells were found in the hydrogel, indicative of ongoing tissue remodeling. At 6 weeks, a typical foreign body response was observed, as demonstrated by numerous fused macrophages (also referred to as foreign-body giant cells) coating the mesh and the permeable membrane (Fig. 8B). We did not observe any significant lymphocytic infiltration around the implant, which would have indicated an activation of chronic inflammation. Of note, microvasculature sprouting was already present after 6 weeks in vivo (Fig. 8B). In contrast to the minimal reaction observed around viable implants, we noticed the formation of a thick avascular 

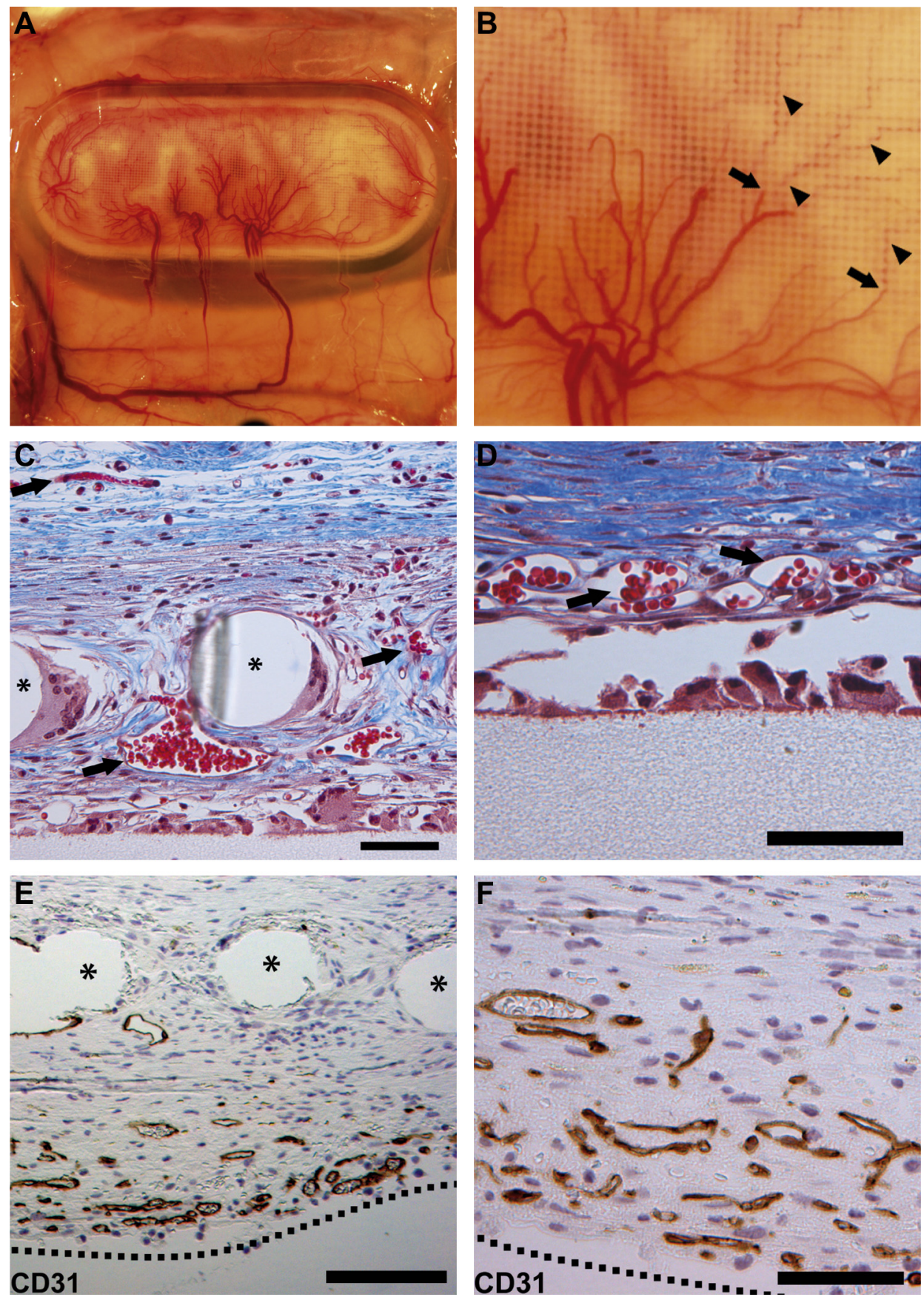

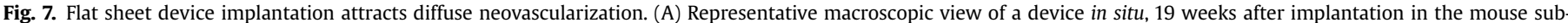

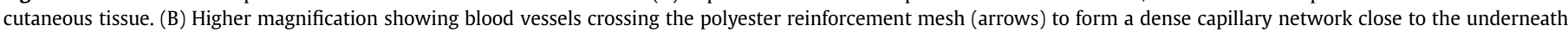

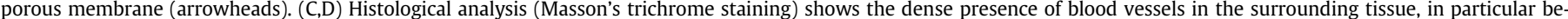

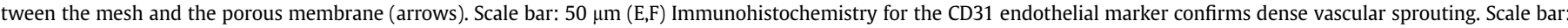
$100 \mu \mathrm{m}(\mathrm{E}), 50 \mu \mathrm{m}$ (F). Dashed line: porous membrane; asterisk: reinforcement mesh (lost during tissue processing).

fibrotic capsule around implants containing a large necrotic core, exemplified by a device initially loaded with $3 \times 10^{6}$ cells analyzed at 19 weeks post-implantation (Fig. 8C). This fibrotic capsule is subsequent to a persistent reaction against foreign material [14] and is typically leading to device failure, for instance by decreasing the diffusion of metabolites $[15,16]$. At 19 weeks after implantation, devices containing viable cells were still surrounded by highly vascularized tissue, with a loose network of collagen fibers consistent with successful capsule engraftment (Fig. 8D).

\section{Discussion}

The delivery of recombinant proteins using allogeneic encapsulated cellular transplants has considerable potential as an alternative to the administration of biotechnologically produced drugs. Here, we have generated an innovative cell encapsulation system comprising an internal chamber for immunoisolating large amount of cells. Ultrasonic welding technology is used to assemble polymer permeable membranes, a reinforcement external mesh and a 

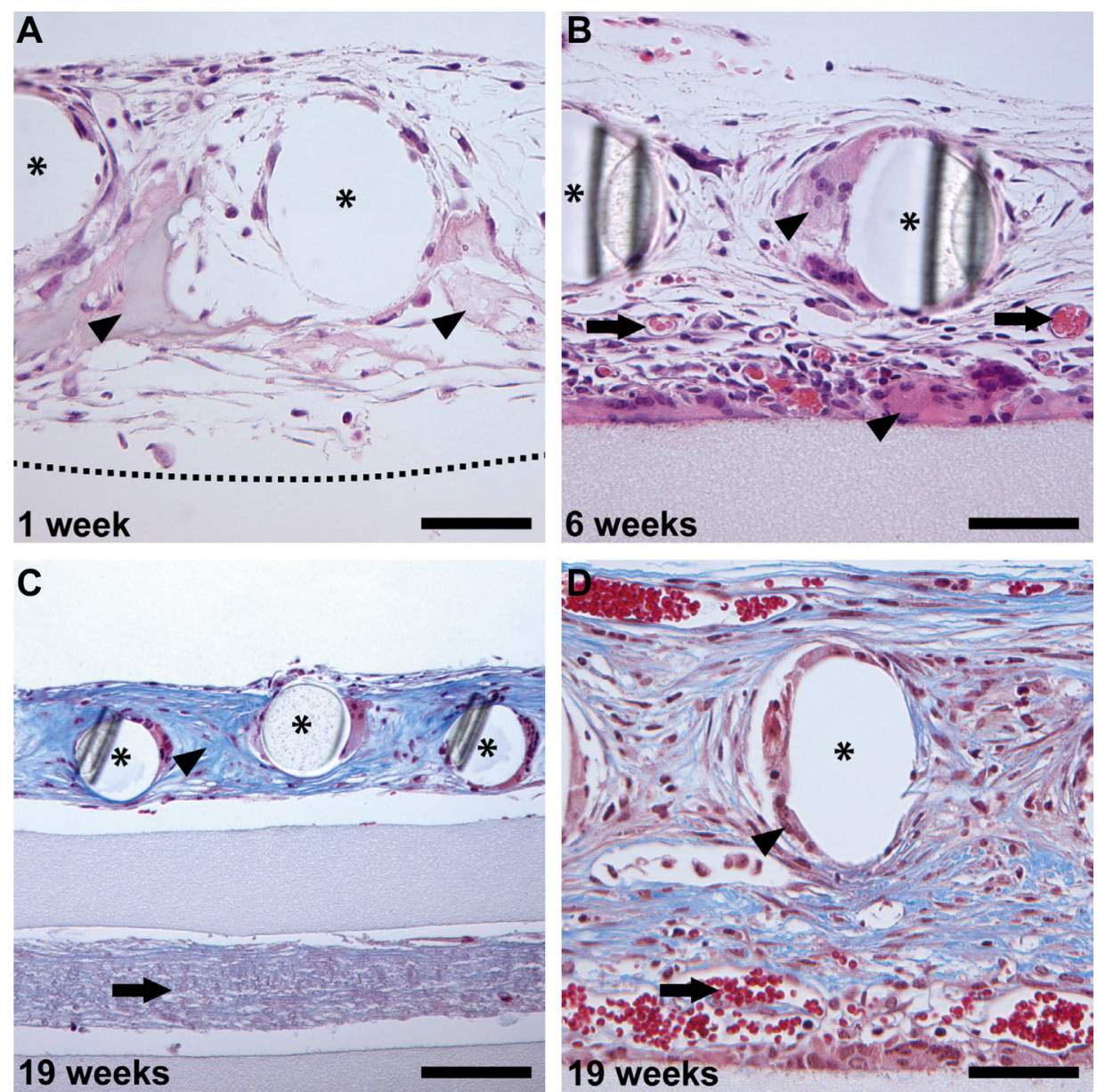

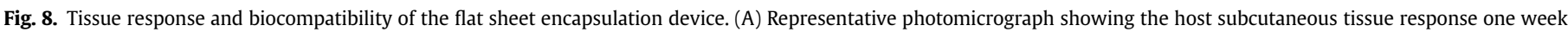

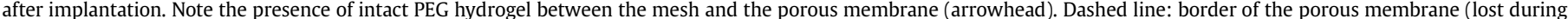

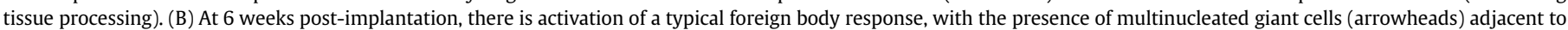

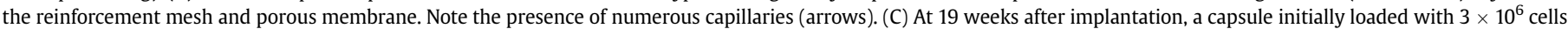

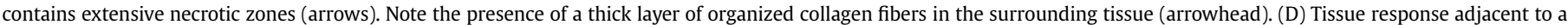

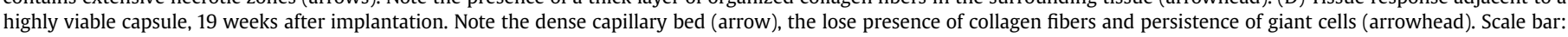
$50 \mu \mathrm{m}$ (A,B,D), $100 \mu \mathrm{m}$ (C). Staining: hematoxylin and eosin (A,B) and Masson's trichrome (C,D). Asterisk: reinforcement mesh (partially lost during tissue processing).

supporting frame, a process compatible with the scale-up of manufacture. Each part of the device is made of medical grade material applicable to clinical development. Here, we describe a capsule devised for implantation in the mouse subcutaneous tissue. Nevertheless, the architecture of the device is readily adaptable to human applications.

It is critical to establish an approach to homogenously distribute the cells seeded inside the device, using an artificial scaffold as a support to favor their expansion. To address this challenge, cells are mixed with an injectable PEG hydrogel with adaptable biological and biophysical characteristics. PEG hydrogel can be tailored for each cell type, for instance by changing PEG concentration to adapt gel stiffness, by adding RGD motifs for integrin binding, or by including MMP domains to make the gel biodegradable [11]. This matrix can support the growth of various cell types such as fibroblasts, osteoblasts or adenocarcinoma cells $[11,17,18]$. Here, we show that biodegradable PEG hydrogel is an effective threedimensional scaffold for the colonization of the device by $\mathrm{C} 2 \mathrm{C} 12$ myoblasts seeded at low density. At an initial concentration of 1.5\% $\mathrm{w} / \mathrm{v}$, the soft PEG hydrogel is almost completely degraded over three weeks. The initial scaffold promotes the alignment of $\mathrm{C} 2 \mathrm{C} 12$ myoblasts into myofiber-like structures, which ultimately produce their own ECM mainly constituted of a complex collagen network.
In the present study, we show that the initial loading parameters determine the long-term outcome of encapsulated cells following implantation. One major determinant for long-term cell viability is the local immune reaction, which can be triggered if encapsulated cells die and liberate substantial amounts of intracellular soluble antigens diffusing across the permeable membrane [19]. Some of these antigens, including extracellular ATP [20] or high-mobility group box 1 protein (HMGP1) [21], can potentially trigger the rejection of the encapsulated graft via an immune process involving the production of cytokines, antibodies or nitric oxide. Preventing early cell death is therefore a priority. The presence of necrotic zones in the central part of encapsulated cell mass typically indicates impaired access to oxygen and nutrients $[5,22,23]$. The oxygen supply to encapsulated cells depends on partial oxygen pressure in the blood and surrounding tissue, proximity to blood vessels, rate of oxygen diffusion into the device, and the rate of oxygen consumption by the cells inside the device. We have found that initial conditions are critical for the concerted proliferation of the encapsulated cells and the development of neovascularization. When cells are loaded at too high density or in the absence of any artificial scaffold, there is rapid expansion in dense cell clusters and formation of a necrotic core during the first weeks of implantation, leading to poor engraftment. Under 
optimized conditions, the growth of cells inside the device parallels the remodeling of host tissue around the capsule and thereby allows for long-term cell survival at high density.

Surprisingly, several months are needed until the cell mass inside the device reaches a steady state. Therefore, longitudinal assessment by quantification of bioluminescence is instrumental to establish initial loading parameters. When compared to the approximate $12-20 \mathrm{~h}$ doubling time of $\mathrm{C} 2 \mathrm{C} 12$ cells in the culture dish, the kinetic of cell expansion inside the device is unexpectedly slow. It is likely that hypoxia inside the implanted device affect myoblast proliferation. Indeed, hypoxia-inducible factors such as HIF- $1 \alpha$ inhibit cell-cycle progression through modulation of $\mathrm{p} 21$ and p27 transcription and $\mathrm{Rb}$ phosphorylation [24]. Hypoxiainduced cell-cycle arrest in G1 phase is however transient in muscle cells, as cell proliferation will resume when normoxia is restored [25]. Under limited oxygen supply, terminal differentiation of $\mathrm{C} 2 \mathrm{C} 12$ cells into myofibers is transiently repressed in vitro, as a function of the degree of hypoxia [26]. Myoblasts have nonetheless the capacity to adapt to hypoxic conditions and recover myogenic potential. This could explain why encapsulated $\mathrm{C} 2 \mathrm{C} 12$ form myofibers following long-term implantation, consistent with the likely increase in oxygen supply promoted by dense neovascularization at later stages. This illustrates the remarkable capacity of engineered C2C12 mouse myoblasts to adapt to restrictive conditions in encapsulation devices, while maintaining a high level of recombinant protein production in vivo (see Ref. [40]) [27,28].

In order to transfer this technology to humans, similar renewable sources of human myogenic cells will need to be identified for allogeneic transplantation. Stem cells could provide an expandable source of myogenic human cells applicable to cell encapsulation. Human mesenchymal stem cells (hMSCs) can be obtained from several sources like bone marrow or adipose tissue and have a high expansion capacity ex vivo [29]. They have been approved for testing in humans (more than 300 registered trials at www. clinicaltrials.gov) and can be produced under controlled conditions [30]. Myogenic differentiation was described in vitro and in vivo [31,32]. Moreover, their ability to express a therapeutic protein after lentiviral transduction has been shown extensively [33-37] (see Ref. [40]). Interestingly, the capacity of hMSCs to respond positively to hypoxia and nutrient deprivation together with their ability to express angiogenic factors was recently reported $[38,39]$. Altogether, hMSC is a promising candidate cell type for the application of cell encapsulation to humans.

\section{Conclusion}

In order to advance cell encapsulation technology towards clinical application, we report the development of a cell macroencapsulation system based on a high-capacity immunoisolation device combined with an injectable artificial extracellular scaffold. Initial hydrogel concentration, cell load and membrane porosity, are critical factors for the long-term survival of encapsulated allogeneic myoblasts at high density in the subcutaneous tissue.

\section{Acknowledgments}

The authors thank Aline Aebi, Fabienne Pidoux, Vivianne Padrun, Christel Sadeghi and Philippe Colin for outstanding technical support, Nicolas Bouche for sharing expertise in device development. This work was supported by the Swiss Commission for Technology and Innovation (CTI project 14666.1 PFLS-LS) and by F. Hoffmann-La Roche Ltd.

\section{References}

[1] Zhang K, Hopkins JJ, Heier JS, Birch DG, Halperin LS, Albini TA, et al. Ciliary neurotrophic factor delivered by encapsulated cell intraocular implants for treatment of geographic atrophy in age-related macular degeneration. Proc Natl Acad Sci U S A 2011;108:6241-5.

[2] Eriksdotter-Jonhagen M, Linderoth B, Lind G, Aladellie L, Almkvist O, Andreasen N, et al. Encapsulated cell biodelivery of nerve growth factor to the basal forebrain in patients with Alzheimer's disease. Dement Geriatr Cogn Disord 2012;33:18-28.

[3] Aebischer P, Schluep M, Deglon N, Joseph JM, Hirt L, Heyd B, et al. Intrathecal delivery of CNTF using encapsulated genetically modified xenogeneic cells in amyotrophic lateral sclerosis patients. Nat Med 1996;2:696-9.

[4] Bachoud-Levi AC, Deglon N, Nguyen JP, Bloch J, Bourdet C, Winkel L, et al. Neuroprotective gene therapy for Huntington's disease using a polymer encapsulated BHK cell line engineered to secrete human CNTF. Hum Gene Ther 2000;11:1723-9.

[5] Schneider BL, Schwenter F, Pralong WF, Aebischer P. Prevention of the initial host immuno-inflammatory response determines the long-term survival of encapsulated myoblasts genetically engineered for erythropoietin delivery. Mol Ther 2003; 7:506-14.

[6] Tarantal AF, Lee CC, Itkin-Ansari P. Real-time bioluminescence imaging of macroencapsulated fibroblasts reveals allograft protection in rhesus monkeys (Macaca mulatta). Transplantation 2009;88:38-41.

[7] Ehrbar M, Rizzi SC, Schoenmakers RG, Miguel BS, Hubbell JA, Weber FE, et al. Biomolecular hydrogels formed and degraded via site-specific enzymatic reactions. Biomacromolecules 2007;8:3000-7.

[8] Ehrbar M, Rizzi SC, Hlushchuk R, Djonov V, Zisch AH, Hubbell JA, et al. Enzymatic formation of modular cell-instructive fibrin analogs for tissue engineering. Biomaterials 2007;28:3856-66.

[9] Rinsch C, Dupraz P, Schneider BL, Deglon N, Maxwell PH, Ratcliffe PJ, et al Delivery of erythropoietin by encapsulated myoblasts in a genetic model of severe anemia. Kidney Int 2002;62:1395-401.

[10] Kishima H, Poyot T, Bloch J, Dauguet J, Conde F, Dolle F, et al. Encapsulated GDNF-producing C2C12 cells for Parkinson's disease: a pre-clinical study in chronic MPTP-treated baboons. Neurobiol Dis 2004;16:428-39.

[11] Bott K, Upton Z, Schrobback K, Ehrbar M, Hubbell JA, Lutolf MP, et al. The effect of matrix characteristics on fibroblast proliferation in 3D gels. Biomaterials 2010;31:8454-64.

[12] Gilbert PM, Havenstrite KL, Magnusson KE, Sacco A, Leonardi NA, Kraft P, et al Substrate elasticity regulates skeletal muscle stem cell self-renewal in culture. Science 2010;329:1078-81.

[13] Broadhead KW, Biran R, Tresco PA. Hollow fiber membrane diffusive permeability regulates encapsulated cell line biomass, proliferation, and small molecule release. Biomaterials 2002;23:4689-99.

[14] Anderson JM. Biological responses to materials. Annu Rev Mater Res 2001;31: $81-110$.

[15] Gerritsen M, Jansen JA, Kros A, Vriezema DM, Sommerdijk NA, Nolte RJ, et al Influence of inflammatory cells and serum on the performance of implantable glucose sensors. J Biomed Mater Res 2001;54:69-75.

[16] Sharkawy A, Klitzman B, Truskey G, Reichert W. Diffusion properties of tissue which encapsulates subcutaneous implants. Abstr Pap Am Chem Soc 1997:213, 342-PMSE.

[17] Ehrbar M, Sala A, Lienemann P, Ranga A, Mosiewicz K, Bittermann A, et al Elucidating the role of matrix stiffness in 3D cell migration and remodeling. Biophys J 2011;100:284-93.

[18] Loessner D, Stok KS, Lutolf MP, Hutmacher DW, Clements JA, Rizzi SC. Bioengineered 3D platform to explore cell-ECM interactions and drug resistance of epithelial ovarian cancer cells. Biomaterials 2010;31:8494-506.

[19] Lanza RP, Langer RS, Vacanti J. Principles of tissue engineering. 2nd ed. San Diego: Academic Press; 2000.

[20] Trautmann A. Extracellular ATP in the immune system: more than just a “danger signal". Sci Signal 2009;2:pe6.

[21] Lotze MT, Tracey KJ. High-mobility group box 1 protein (HMGB1): nuclear weapon in the immune arsenal. Nat Rev Immunol 2005;5:331-42.

[22] Colton CK. Implantable biohybrid artificial organs. Cell Transplant 1995; 415-36.

[23] De Vos P, Van Straaten JF, Nieuwenhuizen AG, de Groot M, Ploeg RJ, De Haan BJ, et al. Why do microencapsulated islet grafts fail in the absence of fibrotic overgrowth? Diabetes 1999;48:1381-8.

[24] Goda N, Ryan HE, Khadivi B, McNulty W, Rickert RC, Johnson RS. Hypoxiainducible factor 1 alpha is essential for cell cycle arrest during hypoxia. Mol Cell Biol 2003;23:359-69.

[25] Di Carlo A, De Mori R, Martelli F, Pompilio G, Capogrossi MC, Germani A Hypoxia inhibits myogenic differentiation through accelerated MyoD degradation. J Biol Chem 2004;279:16332-8.

[26] Yun Z, Lin Q, Giaccia AJ. Adaptive myogenesis under hypoxia. Mol Cell Biol 2005;25:3040-55.

[27] Régulier E, Schneider BL, Déglon N, Beuzard Y, Aebischer P. Continuous delivery of human and mouse erythropoietin in mice by genetically engineered polymer encapsulated myoblasts. Gene Ther 1998:5:1014-22.

[28] Schwenter F, Zarei S, Luy P, Padrun V, Bouche N, Lee JS, et al. Cell encapsulation technology as a novel strategy for human anti-tumor immunotherapy. Cancer Gene Ther 2011;18:553-62. 
[29] Gimble JM, Katz AJ, Bunnell BA. Adipose-derived stem cells for regenerative medicine. Circ Res 2007;100:1249-60.

[30] Sensebe L, Bourin P, Tarte K. Good manufacturing practices production of mesenchymal stem/stromal cells. Hum Gene Ther 2011;22:19-26.

[31] Tian H, Bharadwaj S, Liu Y, Ma H, Ma PX, Atala A, et al. Myogenic differentiation of human bone marrow mesenchymal stem cells on a 3D nano fibrous scaffold for bladder tissue engineering. Biomaterials 2010;31:870-7.

[32] Gang EJ, Jeong JA, Hong SH, Hwang SH, Kim SW, Yang IH, et al. Skeletal myogenic differentiation of mesenchymal stem cells isolated from human umbilical cord blood. Stem Cells 2004;22:617-24.

[33] Meyerrose TE, Roberts M, Ohlemiller KK, Vogler CA, Wirthlin L, Nolta JA, et al Lentiviral-transduced human mesenchymal stem cells persistently express therapeutic levels of enzyme in a xenotransplantation model of human disease. Stem Cells 2008;26:1713-22.

[34] Eliopoulos N, Al-Khaldi A, Crosato M, Lachapelle K, Galipeau J. A neovascularized organoid derived from retrovirally engineered bone marrow stroma leads to prolonged in vivo systemic delivery of erythropoietin in nonmyeloablated, immunocompetent mice. Gene Ther 2003;10:478-89.
[35] Kucic T, Copland IB, Cuerquis J, Coutu DL, Chalifour LE, Gagnon RF, et al. Mesenchymal stromal cells genetically engineered to overexpress IGF-I enhance cell-based gene therapy of renal failure-induced anemia. Am J Physiol Renal Physiol 2008;295:F488-96.

[36] Aslan H, Sheyn D, Gazit D. Genetically engineered mesenchymal stem cells: applications in spine therapy. Regen Med 2009;4:99-108.

[37] Balyasnikova IV, Ferguson SD, Sengupta S, Han Y, Lesniak MS. Mesenchymal stem cells modified with a single-chain antibody against EGFRvIII successfully inhibit the growth of human xenograft malignant glioma. PLoS ONE 2010;5:e9750.

[38] Razban V, Lotfi AS, Soleimani M, Ahmadi H, Massumi M, Khajeh S, et al. HIF1alpha overexpression induces angiogenesis in mesenchymal stem cells. BioRes Open Access 2012;1:174-83.

[39] Liu L, Gao J, Yuan Y, Chang Q, Liao Y, Lu F. Hypoxia preconditioned human adipose derived mesenchymal stem cells enhance angiogenic potential via secretion of increased VEGF and bFGF. Cell Biol Int 2013;37:551-60.

[40] Lathuilière A, Bohrmann B, Kopetzki E, Schweitzer C, Jacobson H, Moniatte M, et al. Genetic engineering of cell lines using lentiviral vectors to achieve antibody secretion following encapsulated implantation. Biomaterials 2014;35:792-802. 